\title{
SISTEM INFORMASI MARKETPLACE PENJUALAN KENDARAAN BERBASIS WEB DI INHIL
}

\author{
Bayu Rianto ${ }^{1}$, Rosliana ${ }^{2}$ \\ ${ }^{1}$ Program Studi Sistem Informasi, Fakultas Teknik dan Ilmu Komputer, Universitas Islam Indragiri, \\ Tembilahan \\ ${ }^{2}$ Program Studi Akuntansi, Fakultas Ekonomi dan Bisnis, Universitas Islam Indragiri, Tembilahan \\ Email: rianto.bayu91@gmail.com (korespondensi)
}

\begin{abstract}
Developments in the field of information technology today have experienced rapid progress, this is inseparable from the existence of the internet. The internet is useful for life activities, one of which is in the business world. Vehicle sales in Tembilahan still market their products simply by leaving it to the sales custody so that costs are wasted and marketing through social media Facebook, WhatsApp and Instagram so that the sales system is not yet effective and many buyers still don't know. A system is needed to analyze and design a vehicle marketplace market information system to make it easier for prospective sellers to market vehicles that they want to sell so that they no longer need to rent a vehicle to sell vehicles and design a vehicle sales marketplace information system that provides a catalog menu so that prospective buyers have no trouble finding vehicles to sell. In this study using PIECES analysis to analyze the old system and the new system, the design process modeling uses context diagrams, DFD (Data Flow Diagrams), ERD (Entity Relationship Diagrams) and system testing using Black box testing and beta testing. In this research it is hoped that later it will be easier for sellers to market vehicles to prospective consumers and make it easier for buyers to find the vehicle they want to buy.
\end{abstract}

Keywords: Marketplace Information Systems, Sales, PIECES Analysis

\begin{abstract}
Abstrak
Perkembangan di bidang teknologi informasi sekarang ini telah mengalami kemajuan secara pesat, hal ini tidak terlepas dari keberadaan internet. Internet bermanfaat bagi aktifitas kehidupan, salah satunya dalam dunia bisnis. Penjualan kendaraan di tembilahan masih memasarkan produknya secara sederhana dengan cara menitipkan ke penitipan penjualan sehingga terbuangnya biaya dan memasarkan melalui media sosial facebook, whatsap dan instagram sehingga sistem penjualannya belum efektif dan banyak pembeli yang masih kurang mengetahui. Diperlukan suatu sistem untuk menganalisa dan merancang sistem informasi marketplace penjualan kendaraan untuk mempermudah calon penjual untuk memasarkan kendaraan yang ingin dijual sehingga tak perlu lagi menyewa tempat untuk menjualan kendaraan serta merancang sistem informasi marketplace penjualan kendaraan yang menyediakan menu katalog sehingga calon pembeli tidak kesulitan mencari kendaraan yang di inginkan. Pada penelitian ini menggunakan analisa PIECES untuk menganalisa sistem lama dan sistem baru, perancangan proses pemodelan menggunakan diagram konteks, DFD (Data Flow Diagram), ERD (Entity Relationship Diagram) dan pengujian sistem menggunakan Black box testing dan pengujian beta. Pada penelitian ini diharapkan nantinya dapat mempermudah penjual untuk memasarkan kendaraan kepada calon konsumen dan mempermudah pembeli untuk mencar kendaraan yang ingin dibeli.
\end{abstract}

Kata kunci: Sistem Informasi Marketplace, Penjualan, Analisa PIECES

\section{PENDAhUlUAN}

Perkembangan di bidang teknologi informasi sekarang ini telah mengalami kemajuan secara pesat, hal ini tidak terlepas dari keberadaan internet. Internet bermanfaat bagi aktifitas kehidupan, salah satunya dalam dunia bisnis.

Marketplace merupakan sebuah pasar virtual dimana pasar tersebut menjadi tempat bertemunya pembeli dan penjual 
untuk melakukan transaksi dan marketplace mempunyai fungsi yang sama dengan sebuah pasar tradisional, perbedaanya adalah marketplace lebih terkomputerisasi dengan menggunakan bantuan sebuah jaringan dalam mendukung sebuah pasar agar dapat dilakukan secara efesien dalam menyediakan update informasi dan layanan jasa utnuk penjual dan pembeli yang berbeda-beda[1]

Penjualan kendaraan di tembilahan masih memasarkan produknya secara sederhana dengan cara menitipkan ke penitipan penjualan penjualan sehingga terbuangnya biaya dan memasarkan melalui media sosial facebook, whatsap dan instagram sehingga sistem penjualannya belum efektif dan pembeli yang masih kurang mengetahui.

Pembeli juga sulit dalam melakukan pencarian kendaraan yang ingin di beli, karena pada sistem penjualan yang ada di forum jual beli tidak menampilkan menu kendaraan sehingga tercampur dengan jenis produk lain dan akan lebih teratur, dengan adanya marketplace para penjual kendaraan lebih mudah memasarkan produk yang akan dijual serta lebih mudah ditemukan oleh para pembeli karena jangkauan pasarnya lebih luas, berbeda dengan sistem menitipkan barang ketempat penjual kendaraan yang ada ditembilahan yang memiliki target pasar hanya orang sekitaran saja.

\section{TINJAUAN PUSTAKA}

\subsection{Penelitian Terdahulu}

Sebuah penelitian tidak muncul begitu saja tetapi ia selalu mencoba menyelesaikan atau menjawab persoalan yang ditinggalkan oleh peneliti sebelumnya. Keterkaitan inilah yang jika dirangkai secara menyeluruh peneliti dapat mengetahui yang kita sedang teliti dengan penelitian sebelumnya.

Pada tahun 2016 dilakukan penelitian PERANCANGAN SISTEM INFORMASI PENJUALAN BERBASIS WEB DALAM MEMASARKAN MOBIL BEKAS oleh Sandy Kosasi [2]. Berdasarkan hasil penelitian yang sedang berlangsung disini penulis menggunakan perancangan sistem penjualan mobil bekas berbasis web dengan menggunakan metode ICDM diawali dengan tahapan analisis SWOT. Penggunaan analisis SWOT untuk mengidentifikasi dan memperbaiki kelemahan-kelemahan dalam sistem berjalan sebelumnya. Analisa SWOT dijabarkan ke dalam empat tingkatan yaitu, menjabarkan kekuatan (strengths), kelemahan (weaknesses), peluang (environmental opportunities) dan ancaman yang mungkin terjadi (threats).

Pada tahun 2017 dilakukan penelitian PERANCANGAN SISTEM INFORMASI PENJUALAN SUKU CADANG MOBIL BERBASIS WEB STUDI KASUS : KREASI AUTO PARTS oleh Astri Wardani dan Retno Sari [3]. Berdasarkan hasil penelitian yang sedang berlangsung disini peneliti hanya berfokus pada system penjualan suku cadang mobil dan metode penelitian yang digunakan oleh peneliti yaitu metode penelitian kualitatif yaitu peneliti melakukan penelitian dengan melakukan observasi dan studi lapangan dengan melihat secara langsung proses penjualan yang terjadi pada Kreasi Auto Parts. Model pengembangan sistem yang digunakan adalah waterfall serta pada tahap pengujian sistemnya penulis hanya menggunakan Black Box Sistem.

Pada tahun 2018 dilakukan penelitian SISTEM INFORMASI PENJUALAN MOBIL BERBASIS WEB DENGAN MEMANFAATKAN METODE VISUAL ARCHITECTING PROCESS (Studi Kasus : CV. Cahaya Mobilindo) oleh Hendra Di Kusuma [4]. Berdasarkan penelitian yang sedang berlangsung disini peniliti melakukan pengembangan sistem dengan menggunakan UML (Univied Modeling Language) serta memanfaatkan metodologi Visual Architecting Process yang mampu menyediakan layanan informasi yang ditanam pada handphone teknologi flashlite dan memberikan kemudahan dalam hal berpromosi dan melakukan perhitungan kredit

\subsection{Sistem Informasi}

Sistem informasi adalah seperangkat komponen yang saling berhubungan dan saling bekerja sama untuk mencapai beberapa tujuan. Selain itu Sistem Informasi diartikan secara teknis adalah komponen yang saling terkait yang mengumpulkan atau menelusuri, memproses, menyimpan dan mendistribusikan informasi guna mendukung pengambilan keputusan dan kontrol di dalam suatu organisasi [5].

\subsection{Sistem}

Sistem adalah suatu kesatuan yang dan terdiri dari berbagai faktor yang berhubungan atau diperkirakan berhubungan serta satu sama lain saling mempengaruhi, yang kesemuanya dengan sadar dipersiapkan untuk mencapai tujuan yang telah ditetapkan[6]. 


\subsection{Informasi}

Informasi adalah data yang diolah dan berguna bagi pemakai. Terkadang informasi juga dapat dimaknai sebagai proses lebih lanjut dari data dan memiliki nilai tambah [7].

\subsection{Marketplace}

Marketplace adalah aplikasi atau situs web yang memberi fasilitas jual beli online dari berbagai sumber. Pemilik situs web atau aplikasi tidak memiliki produk apapun dan bisnis mereka hanya menyajikan produk orang lain kepada pengguna kemudian memfasilitasinya [8]

\subsection{Penjualan}

Penjualan adalah kegiatan yang dilakaukan oleh penjual dalam menjual barang atau jasa dengan harapan akan memperoleh laba dari adanya tarnsakasitransaksi tersebut dan penjualan dapat diartikan sebagai pengelihan atau pemindahan hak kepemilikan atas barang atau jasa dari pihak penjual ke pembeli. menurut [9].

\subsection{Web}

Website atau situs juga dapat diartikan sebagai kumpulan halaman yang menampilkan informasi data teks, data gambar diam atau gerak, data animasi, suara, video dan atau gabungan dari semuanya, baik yang bersifat statis maupun dinamis yang membentuk satu rangkaian bangunan yang saling terkait dimana masing-masing dihubungkan dengan jaringan-jaringan halaman (hyperlink)[6]

\section{Metode Penelitian}

\subsection{Alur Penelitian}

Alur penelitian adalah kronologi prosedural yang dilakukan seorang peneliti dalam karya penelitiannya dan bukan sekedar urutan apa yang mesti dilalui. Alur penelitian lebih merupakan strukturisasi atau hubungan metodologi yang berkesinambungan dan tujuannya adalah agar tetap bisa menjaga fokus pada masalah serta memudahkan untuk mencapai tujuan penelitian. Juga agar diharapkan bisa dipertahankan antara keterkaitan dan keberlanjutan pada setiap masing-masing tahap-tahapan penelitian.

Alur penelitian dalam penulis skripsi ini menjelaskan mengenai tahapan-tahapan penelitian yang di mulai dari pengumpulan data melalui observasi, wawancara dan studi literatur, perancangan pemodelan sistem menggunakan perancangan Konteks Diagram, DFD (Data Flow Diagram), ERD (Entity Realationship Diagram) dan analisa perancangan system menggunakan analisa PIECES (performance, information, economy, control, eficiency, service).

\subsection{Data}

Metode pengumpulan data yang digunakan untuk mendapatkan data dari suatu informasi, maka yang digunakan dalam pengumpulan data penelitian ini adalah :

1. Metode Observasi (pengamatan)

Pada metode ini, peneliti melakukan obesrvasi di forum jual beli yang ada di social media seperti facebook dan melakukan pengamatan langsung di tempat jual beli kendaraan bekas.

2. Wawancara

Pada metode ini, peneliti melakukan tanya jawab (wawancara) langsung kepada beberapa masyarakat dan kepada para penjual dan pembeli kendaraan untuk mendapatkan data dan informasi yang peneliti perlukan.

3. Studi Pustaka

Pada metode ini, peneliti mencari sumber-sumber tulisan dan mempelajari referensi-referensi berupa jurnal yang berhubungan dengan penelitian ini, guna untuk melengkapi penelitian dan menambah informasi yang dibutuhkan.

\section{Hasil dan Pembahasan}

\subsection{Hasil Analisa}

Analisa sistem di gunakan untuk mengambil keputusan. Apabila sistem ini mempunyai masalah atau sudah tidak berfungsi secara baik,dan hasilnya digunakan sebagai dasar untuk memperbaiki sistem. Permesalahan-permasalahan yang ditemukan pada saat analisa sistem ini dapat diatasi dengan mengadakan perubahanperubahan dengan cara merancang sistem baru.

\subsection{Analisa PIECES}

Analisa PIECES ini di gunakan untuk menganalisa beberapa hal yang dari situ akan disimpulkan masalah utama yang ada di studi kasus secara jelas dari hasil analisis akan dapat dirumuskan berbagi usulan untuk membantu perancangan sistem yang lebih baik.

1. Analisa Kinerja (Performance) 
Analisa kinerja pada sistem yang sedang berjalan pada saat ini permasalahan yang dihadapi adalah penjual kendaraan tidak memiliki cakupan wilayah yang luas untuk menjual kendaraannya, sehingga yang mengetahui hanya di wilayah sekitar penjual kendaraan saja, begitu juga dengan proses pembuatan laporan penjualan kendaraan pemilik kendaraan hanya mencatat dibuku saja, sehingga waktu yang diperlukan relatif lama dan bisa saja catatan laporan bisa hilang. Pada sistem yang akan dibangun yaitu marketplace penjualan kendaraan berbasis web disini penjual sudah memiliki cangkupan wilayah pemasaran yang lebih luas dan tidak terbatas, begitu juga dengan laporan penjualan kendaraan sudah tersedia di sistem baik itu laporan kendaraan baru, laporan kendaran diterima, laporan kendaran laku atau terjual dan laporan kendaraan ditolak, jadi para penjual atau member tidak perlu lagi mencatat laporan dibuku.

2. Analisa Informasi (Information)

Analisa informasi pada sistem yang sedang berjalan pada saat ini memiliki permasalahan seperti pembeli kurang mengetahui detail keterangan kendaraan, spesifikasi kendaraan (tipe kendaraan, cakupan mesin, transmisi, bahan bakar dan spesifikasi lainnya) dan deskripsi lengkap mengenai kendaraan yang dijual karena penjual kendaraan memasarkan kendaraannya di media sosial dan hanya mengunggah gambar saja tanpa keterangan lengkap mengenai kendaraan yang dijual, pembeli juga kesulitan dengan proses pencarian kendaraan yang ingin di beli karna unggahan gambar yang tercampur dengan produk lain dan tidak teratur. Pada sistem yang akan dibangun yaitu marketplace penjualan kendaraan berbasis web disini pembeli dapat mengetahui dengan lengkap mengenai spesifikasi kendaraan dan deskripsi lengkap mengenai kendaraan yang dijual oleh member, apabila ada member yang memasarkan kendaraanya tidak memberikan spesifikasi mengenai kendaraan dan deskripsi lengkap maka admin tidak akan menerima kendaraan untuk dipasarkan.

3. Analisa ekonomi (Economy)

Pada sistem yang berjalan pada saat ini berdasarkan analisa ekonomi memiliki permasalahan seperti penjual kendaraan menitipkan kendaraan yang ingin dijual sehingga membutuhkan biaya lagi untuk jasa titip, begitu juga dengan wilayah jangkauan untuk memasarkan kendaraannya kurang luas sehingga para pembeli kurang mengetahui kendaraan yang dijual. Pada sistem yang akan dibangun yaitu marketplace penjualan kendaraan berbasis web penjual kendaraan hanya memerlukan paket internet saja untuk memasarkan kendaraannya di sistem dan memberikan keterangan lengkap mengenai kendaraan yang ingin dijual seperti spesifikasi dan deskripsi lengkap agar kendaraan yang ingin dipasarkan diterima oleh admin, setelah kendaraan yang dipasarkan telah diterima oleh admin untuk ditampilkan maka jangakuan wilayah yang dapat mengetahui lebih luas.

4. Analisa Pengendalian (Control)

Pada sistem yang berjalan pada saat ini berdasarkan analisis pengendalian system memiliki permasalahan terhadap profil penjual yang memasarkan kendaraannya di media social, dimana para penjual tidak melampirkan alamat, no telp dan surat -surat kendaraan serta sudah berapa iklan yang di pasarkan di media social sehingga pembeli ragu untuk bertanya untuk membeli kendaraan yang dijual, begitu juga dengan kendaraan yang dipasarkan dimedia sosial tidak ada yang memverifikasi sehingga penjual tinggal mengunggah nya saja mau itu kendaraan yang memiliki surat-surat lengkap maupun kendaraan kosong (tidak memiliki surat). Pada sistem yang akan dibangun yaitu marketplace penjualan kendaraan berbasis web dimana para member sebelum memasarkan kendaraannya di sistem harus registrasi terlebih dahulu sperti melengkapi profil member yang telah disediakan oleh sistem apabila ada member yang tidak memasukkan dengan lengkap profilnya maka iklan yang ingin dipasarkan tidak akan diterima oleh admin begitu juga dengan surat-surat kendaraan apabila tidak dilampirkan oleh member maka kendaraan yang ingin dipasarkan tidak akan diterima, kendaraan yang telah ditampilkan oleh sistem merupakan kendaraan yang terverifikasi oleh admin.

5. Analisa Efesiensi (Eficiency)

Pada sistem yang sedang berjalan pada saat ini berdasarkan analisis efesiensi 
memiliki permasalahan terhadap penjual yang kurang memiliki cangkupan yang luas untuk memasarkan kendaraannya oleh karena itu cara memasarkan kendaraan masih kurang efesien, tidak hanya itu pembuatan laporan pesanan masih dibuat secara manual, sehingga membutuhkan waktu yang lama. Pada sistem yang akan dibangun penjualan kendaraan berbasis web ini semua member bisa memasarkan kendaraannya di sistem, cakupan wilayah menjadi lebih luas sehingga banyak yang mengetahui kendaraan yang dijual oleh member dan laporan penjualan dapat di cetak waktu kapan saja tinggal dipilih dari tanggal berapa sampai tanggal berapa laporan yang ingin dicetak.

6. Analisa Pelayanan (Service)

Pada sistem yang berjalan pada saat ini berdasarkan analisa pelayanan memiliki permasalahan terhadap pembeli yang tidak dapat mengetahui mengenai spesifikasi kendaraan, deskripsi lengkap mengenai kendaraan yang dijual dan tidak mengetahui apakah penjual sudah terverifikasi atau belum di social media. Pada sistem yang akan dibangun terdapat spesifikasi kendaraan, deskripsi lengkap kendaraan dan suratsurat kendaraan, apabila ada pengunjung yang mau mendaftar sebagai member tetapi tidak melangkapi profil sebagai member maka admin akan menolak iklan dan bisa saja member diblokir oleh admin sehingga tidak akan bisa lagi untuk memasarkan kendaraannya di sistem.

\subsection{Implementasi Sistem}

Hasil implementasi dari pada perancangan applikasi sistem informasi marketplace penjualan kendaraan berbasis web di Inhil merupakan antar muka untuk berinteraksi antara user dengan sistem. Semua halaman iplementasi ini dapat di akses melalui halaman browser.

1. Tampilan Halaman Utama Aplikasi

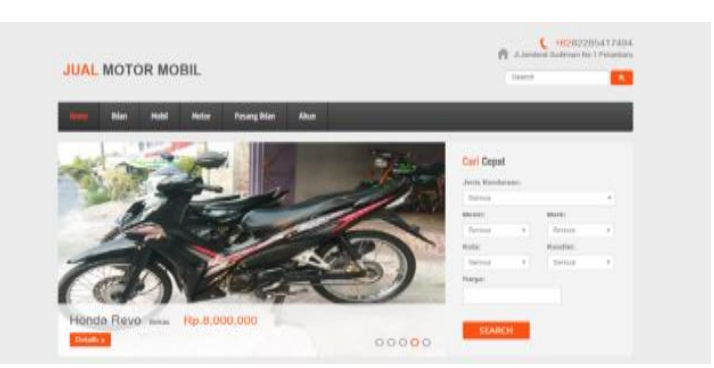

Gambar 1. Tampilan Halaman Utama Aplikasi

\section{Tampilan Halaman Daftar Member}

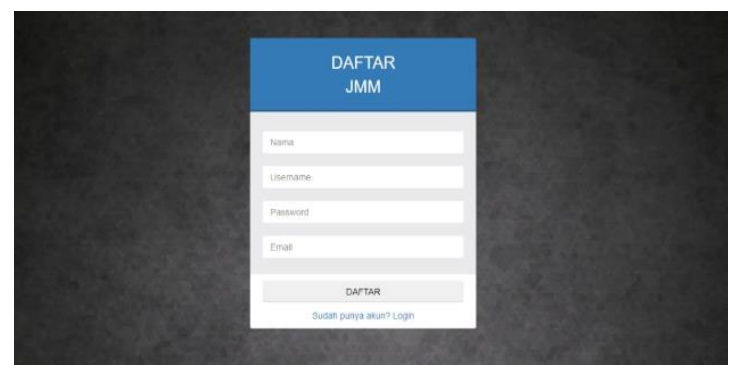

Gambar 2. Tampilan Halaman Daftar Member

\section{Tampilan Halaman Login}

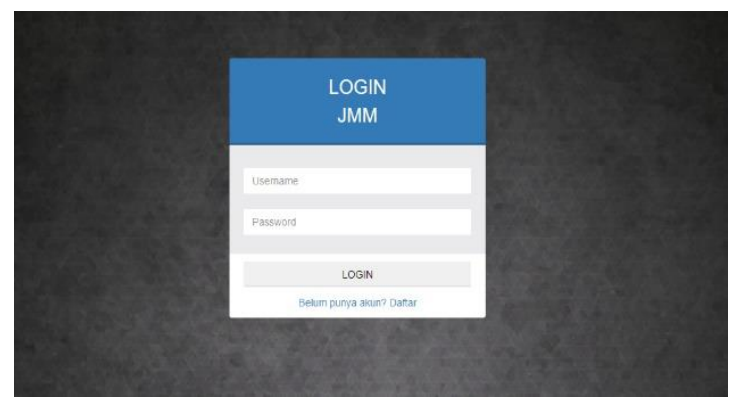

Gambar 3. Tampilan Halaman Login

4. Tampilan Halaman Dashboard Admin

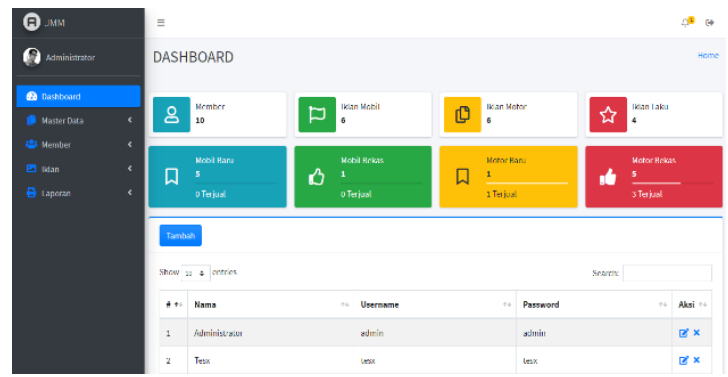

Gambar 4. Tampilan Halaman Dashboard Admin

\section{Kesimpulan}

Berdasarkan hasil dan pembahasan yang tela dipaparkan ditarik kesimpulan bahwa dengan adanya sistem ini dapat mempermudah penjual untuk memasarkan kendaraan kepada calon konsumen, 
mempermudah pembeli untuk mencari kendaraan yang akan dibeli dan dengan adanya sistem ini mempermudah masyarakt untuk mendapatkan informasi tentang kendaraan yang ingin dibeli.

\section{Daftar Pustaka}

[1] B. R. Betti Dame Hutauruk, Jimmy Febrianus Naibaho, "Analisis dan Perancangan Aplikasi Marketplace Cinderamata khas Batak Berbasis Android," J. Method., vol. 3, no. 1, pp. 242-246, 2017.

[2] S. Kosasi, "Perancangan Sistem Informasi Penjualan Berbasis Web Dalam Memasarkan Mobil Bekas," J. Creat. Inf. Technol., vol. 3, no. 1, pp. 1-14, 2015, doi: 10.24076/CITEC.2015V3I1.61.

[3] Jamaludin and $H$. Sugiarto, "Perancangan Sistem Informasi Penjualan Suku Cadang Sepeda Motor Berbasis Web," J. Bianglala Inform., vol. 5, no. 1, pp. 21-29, 2017.

[4] H. Di Kesuma, "Sistem Informasi Penjualan Mobil Berbasis Web dengan Memanfaatkan Metode Visual Architecting Process TM ( Studi Kasus: $\mathrm{CV}$. Cahaya Mobilindo )," J. IIm. Inform. Glob., vol. 09, no. 2, pp. 106$111,2018$.

[5] Mardison, "Perancangan Sistem Informasi Pembelian E- Data Grafik Pada CV . Tranex Mandiri Kota," J. Teknol., vol. 7, no. 1, pp. 150-161, 2017.

[6] B. Rianto, "Perancangan Apliksi Pengolahan Data Berkas Pajak pada Kpp Pratama Pekanbaru Berbasis Desktop," Sistemasi, vol. 7, no. 1, pp. 48-55, 2018.

[7] A. Burrahman, "MEMBANGUN SISTEM INFORMASI AKADEMIK BERBASIS WEB PADA PONDOK PESANTREN SALAFIYAH AL-BAQIYATUSSA'DIYYAH

TEMBILAHAN," SISTEMASI, vol. 6, no. 1 , p. 33, May 2018, doi: 10.32520/stmsi.v6i1.26.

[8] P. Artaya and T. Purworusmiardi, "Efektifitas Marketplace Dalam Meningkatkan Konsentrasi Pemasaran dan Penjualan Produk Bagi UMKM di Jawa Timur," no. April, 2019, doi: 10.13140/RG.2.2.10157.95206.

[9] A. Praelsetyo and R. Susanti, "Sistem Informasi Penjualan Berbasis Web Pada PT. Cahaya," J. IIm. Teknol. Inf. Asia, vol. 10, no. 2, pp. 1-16, 2016. 